\title{
TECNOLOGIAS MÓVEIS, MÍDIAS E REDES SOCIAIS: CULTURA DE USO DE ESTUDANTES DE LICENCIATURA
}

\author{
Simão Pedro Pinto Marinho ${ }^{1}$, Fernanda de Jesus Costa², Flávia Cardoso \\ Carneiro $^{3}$, Paula Andréa de Oliveira e Silva Rezende ${ }^{4}$, Ricardo Nicolau ${ }^{5}$,
}

${ }^{1}$ Programa de Pós-Graduação em Educação - Pontifícia Universidade Católica de Minas Gerais (PUC MINAS) - Campus Coração Eucarístico - Avenida Dom José Gaspar 500 30.535-901 - Belo Horizonte - MG - Brasil

${ }^{2}$ Universidade do Estado de Minas Gerais - Ibirité - MG - Brasil

${ }^{3}$ Centro Universitário UNA - Belo Horizonte - MG - Brasil

${ }^{4}$ Instituto Federal de Educação, Ciência e Tecnologia de Minas Gerais - Ribeirão das Neves - MG. Pontifícia Universidade Católica de Minas Gerais - Unidade São Gabriel e campus Coração Eucarístico. Belo Horizonte - MG

${ }^{5}$ Programa de Pós-Graduação em Educação - Pontifícia Universidade Católica de Minas Gerais (PUC MINAS) Campus Coração Eucarístico - Belo Horizonte - MG - Brasil

marinhos@pucminas.br, fernandinhajc@yahoo.com.br, flaviacar@yahoo.com, paulaandrea@uai.com.br, ricnic.br@gmail.com

ABSTRACT. The mobile technology is changing the way people communicate in the last decade. People's lives was invaded by devices of all types and sizes which, despite the challenges of adjustment they bring, also offer numerous possibilities of innovation to everyday life. Mobile technology and various applications, especially those of communication and collaboration, such as social media, in turn, need to be considered in the challenge to transform the school so that teachers and students can enjoy the many benefits that the technology offers. To prepare teachers for using these technologies is one of the latest challenges. However, this training will be facilitated to the extent that undergraduate students do routine use of these technologies, creating an intimacy that reduces fears of its application in the classroom. This study provides a picture of the use of mobile technologies and social media for undergraduate students

RESUMO. A tecnologia móvel vem mudando a maneira como as pessoas se comunicam na última década. A vida das pessoas foi invadida por aparelhos de todos os tipos e tamanhos os quais, apesar dos desafios de adaptação que trazem, oferecem também inúmeras possibilidades de inovação para a vida cotidiana. A tecnologia móvel e diversos aplicativos, especialmente os de comunicação e colaboração, como as mídias sociais, por sua vez, precisam ser considerados no desafio de transformar a escola para que professores $e$ estudantes possam usufruir dos muitos benefícios que a tecnologia oferece. 


\title{
CBIE-LACLO 2015
}

Anais dos Workshops do IV Congresso Brasileiro de Informática na Educação (CBIE 2015)

\begin{abstract}
Preparar professores para o uso dessas tecnologias é um dos mais recentes desafios. Contudo, essa formação será facilitada na medida em que os estudantes de licenciaturas façam uso rotineiro dessas tecnologias, criando uma intimidade que diminui receios de sua aplicação nas salas de aula. $O$ presente estudo traça um retrato do uso de tecnologias móveis e de mídias sociais por estudantes de licenciatura.
\end{abstract}

\section{Introdução}

A tecnologia digital da informação e comunicação (TDIC), disseminada em escola global, vem modificando, desde os anos 1980, a maneira como as pessoas se informam, aprendem, criam e interagem. Desde o seu surgimento, diversas foram as iniciativas para integrá-las ao currículo escolar. Entretanto, o ritmo em que elas surgem e se modificam parece superar a capacidade da escola de se apropriar delas. Nos primeiros anos do séc. XXI, enquanto educadores debatiam se o uso educativo do computador traria resultados que justificassem investimentos em infra-estrutura e formação de professores, surgiram as tecnologias de conexão "sem fio" e os dispositivos móveis. Um grande número de pessoas passou a fazer uso desses dispositivos e alterou significativamente seu comportamento. Inevitavelmente, chega à escola essa nova onda tecnológica e ocorre uma curiosa mudança no cenário de inclusão curricular das tecnologias digitais. Se no fim do século XX, discutiam-se alternativas para superar a ausência da tecnologia digital na escola e um dos problemas era o fato de que elas era acessível a poucos alunos, com a popularização dos dispositivos móveis ganha destaque no debate a sua presença na sala de aula. Agora são os alunos que trazem consigo os seus dispositivos e, não raro, causando transtornos, perturbando ambientes de aprendizagem. Como consequência natural, surgem considerações sobre o uso educacional das tecnologias digitais móveis de informação e comunicação (TDMIC), alguns mais ousados fazem tentativas de inclusão curricular dessas tecnologias, enfim, (re)acende-se o debate da pertinência do uso educativo desse tipo das tecnologias digitais de informação e comunicação (TDIC). Nesse sentido, a formação de professores permanece como foco central de atenção da questão do uso das TDIC na escola, pela importância que tem o professor na escolha dos caminhos que educação percorrerá. Afinal, serão eles os sujeitos que ajudarão a construir a nova escola, a escola do novo século.

\section{Tecnologias móveis}

Na segunda metade da primeira década deste século, surgiu uma nova onda tecnológica global: as Tecnologias Digitais Móveis de Informação e Comunicação (TDMIC). Favorecidas pelo desenvolvimento de tecnologias de comunicação sem fio (3G, 4G e WiFi) e por suas dimensões reduzidas, as TDMIC se destacam pela portabilidade: são de propriedade e controle de um indivíduo e não de uma instituição (UNESCO, 2013) e o usuário pode carregá-las consigo (CORSO, 2013). Assim, permitem acesso à Internet onde houver serviço de telefonia móvel $(3 \mathrm{G} / 4 \mathrm{G})$, ou um ponto de acesso Wi-Fi.

As TDMIC favorecem diversas mudanças na sociedade e ainda o surgimento de um novo paradigma: a mobilidade. "Este novo paradigma vem modificando a forma como se trabalha, se estuda, se comunica, se diverte, e outras atividades quando se está em movimento, ou em momento que não quer ficar limitado a uma determinada 


\section{CBIE-LACLO 2015}

Anais dos Workshops do IV Congresso Brasileiro de Informática na Educação (CBIE 2015)

infraestrutura fixa de comunicação (CORSO, 2013). Algumas das TDMIC mais populares atualmente são o smartphone, o tablet e os leitores de livro digital (e-reader), além dos aparelhos portáteis de áudio (MP3) e dos consoles manuais de videogame.

Atualmente as TDMIC estão presentes em praticamente todo o mundo, oferecendo funcionalidades multimídia, facilitando um grande número de tarefas, particularmente aquelas relacionadas à comunicação (UNESCO, 2013). Geralmente mais baratas que os computadores (desktop ou laptop), as TDMIC se disseminaram rapidamente. No Brasil, em 2013, foram 111,3 milhões de conexões por dispositivos móveis contra 20,2 milhões de conexões por dispositivos fixos (GSMA, 2014). O mesmo estudo da GSMA traz outros dados interessantes: estima-se que em 2016 o número de tablets vendidos superará o número de notebooks; e ainda em 2015 o Brasil deverá superar o Japão tornando-se o país com o quarto maior número de acessos à internet via smartphones.

A convergência tecnológica em torno dos dispositivos móveis tornou muito similar a operação e a aprendizagem no uso de praticamente qualquer TDMIC (BROUGÈRE; ULMANN, 2012), acelerando o aprendizado de seus usos. Com a convergência de mídias, uma única plataforma tecnológica é capaz de prover diversos serviços midiáticos híbridos, suportando diversos canais de comunicação simultaneamente com o uso de variados App.

Os app são aplicativos desenvolvidos para uso nos dispositivos móveis. Pela praticidade e simplicidade, os App se tornaram uma interessante alternativa ao modelo de aplicações complexas que nas últimas quatro décadas somente podiam ser construídas por programadores experientes, para uso quase exclusivo nos computadores. Hoje em dia, com o auxílio de fábricas de App, não é necessário um conhecimento aprofundado de linguagens de programação de computadores para que alguém seja capaz de desenvolver um App que atenda determinada necessidade.

Valendo-se da disseminação das TDMIC e dos app, popularizaram-se as mídias e redes sociais que já ocupavam, de alguma forma, uma posição destacada na sociedade tecnológica (MACHADO, TIJIBOY, 2005). Redes e mídias sociais apresentam relação com comunidades virtuais que podem ser entendidas como redes eletrônicas interativas de comunicação que apresentam interesse ou finalidade compartilhados, sendo que a comunicação pode ser o próprio objetivo (CASTELLS,1999). Entretanto, redes sociais e mídias sociais são conceitos distintos.

As redes sociais podem ser formadas por pessoas que compartilham objetivos comuns e não precisam estar limitadas a uma estrutura hierárquica e podem estar presentes na escola, no trabalho, na música, na política (CIRIBELI, PAIVA, 2011). As redes sociais, portanto, constituem-se como grupos de pessoas que se comunicam virtualmente fazendo uso de uma ou várias mídias sociais.

A mídia social tem relação com o tipo de tecnologia que se utiliza como suporte para que os integrantes de redes sociais possam se comunicar. A mídia social é algo mais amplo que rede. É a mídia que permite o surgimento das redes sociais. Existem diferentes tipos de mídias, as quais apresentam diferentes finalidades e públicos, estas podem ter como foco contatos profissionais, relacionamentos, pesquisas. As mídias apresentam ferramentas que facilitam a comunicação entre os usuários, favorecendo a integração de conteúdos, postagens e compartilhamentos (CIRIBELI, PAIVA, 2011). As mídias sociais 


\section{CBIE-LACLO 2015}

Anais dos Workshops do IV Congresso Brasileiro de Informática na Educação (CBIE 2015)

são mais amplas e compartilham diferentes conteúdos, permitindo a formação de redes sociais ou não (ROCHA, ALVES, 2010).

As redes sociais cresceram nos últimos anos devido ao advento da Web 2.0 (BARCELOS, 2012). E a cada dia cresce ainda mais o número de pessoas que utilizam redes e mídias sociais (MACHADO, TIJIBOY, 2005; CIRIBELI, PAIVA, 2011; BARCELOS, 2012), em diferentes cenários e com objetivos distintos. Com esta expansão, por um lado verificamos a formação de redes sociais bem definidas, com perfis variados, facilitando que o usuário expresse suas opiniões e compartilhe ideias, por outro, favorece o crescimento de problemas virtuais tais como o cyberbullying (CIRIBELI, PAIVA, 2011).

As mídias e redes sociais encontram-se nos mais variados ambientes. Especificamente no ambiente escolar apresentam diversas possibilidades nos processos de ensino e de aprendizagem (BARCELOS, 2012; PESSONI, AKERMAN, 2014). Elas podem contribuir para a mobilização dos saberes, favorecem o reconhecimento das identidades e a articulação dos pensamentos que estão presentes na sociedade (MACHADO, TIJIBOY, 2005). A rede social que vem se destacando no ambiente escolar é o Facebook (PESSONI, AKERMAN, 2014). Contudo, uma pesquisa documental (PESSONI, AKERMAN, 2014), com 37 trabalhos envolvendo a utilização de mídias sociais no ambiente escolar, demonstrou que esta utilização é ainda pequena, faltam conhecimento e pesquisas na área. Os autores destacaram também que ainda existe certo receio na manutenção de relações sociais entre aluno e professor em ambientes virtuais.

O potencial de uso educativo das TDMIC permite que se pense em currículos escolares que façam uso intensivo destas tecnologias. Uma destas propostas é o App Currículo ou Currículo 4G em que, ao fazer uso das TDMIC, "a qualquer momento, em qualquer lugar, pode-se abrir uma 'janela' para ver o mundo, uma 'porta' para entrar no mundo, criando oportunidades de aprender e de mostrar o que se aprendeu" (MARINHO et al, 2014, p. 6). Portanto, o uso educativo das TDMIC abre possibilidades para que se pense em ensino e aprendizagem ubíquos.

Para que esta utilização aconteça no ambiente escolar de forma eficaz é preciso investir na formação docente, seja ela inicial ou continuada. É preciso que os professores em formação percebam as tecnologias digitais como uma possibilidade de ampliar os espaços educativos, permitindo uma descentralização do acesso ao saber, aproximando alunos e professores (BARCELOS, 2012).

\section{Tecnologias móveis e a formação de professores}

Ao pensar as Tecnologias Digitais Moveis de Informação e Comunicação (TDMIC) e os cursos de licenciaturas se observa um paradoxo entre os discursos propostos para os cursos de formação de professores e a prática educacional na sala de aula. $\mathrm{O}$ uso das tecnologias, como recurso educacional, não está previsto na Lei 9394/96 que regulamenta as Diretrizes e Bases da Educação Nacional. Em 2006 o Governo Federal criou o Programa de Consolidação das Licenciaturas (PRODOCÊNCIA) com o objetivo principal de fomentar e elevar a qualidade dos cursos de formação de professores no país enfatizando o "apoio à criação de metodologias inovadoras para os cursos de 
licenciatura". Entretanto os resultados do programa de 2010 não evidenciam ações com o uso das tecnologias ${ }^{1}$.

Ferrete e Ferrete (2014) argumentam que os professores necessitam de uma educação contínua para o uso da TDMIC, assim como de uma reflexão sobre a sua prática educativa com o uso das tecnologias com o objetivo de mapear as dificuldades encontradas e descobrir possíveis soluções.

Serpa (1999, p. 27) já vislumbrava o desafio da formação de professores no Século XXI quando afirmou, a frase transcrita a seguir, ainda no Século passado e que continua atual

Este é o grande desafio do próximo milênio: capacitar o corpo docente para novas mudanças da Educação. Sem dúvida, essa capacitação só poderá ser feita, com a velocidade de que precisa e com a qualidade que se exige. [...] precisamos reconstruir a escola dos professores.

Mas como reconstruir a escola dos professores em uma sociedade dominada pela tecnologia, na maioria de suas ações e com um perfil de aluno altamente tecnológico, com acesso as redes sociais, a internet e, a um grande número de informações que geram no discente um sentimento de conhecimento, pela facilidade de acesso? Como formar estes alunos para o uso da tecnologia como recurso educacional, se na prática esse uso ferramental já é rotineiro?

Constata-se a necessidade de mudança na estrutura dos cursos de formação de professores, em sua prática educativa, no que tange às concepções de ensino, de tecnologia, de educação e do ensino com uso das TDMIC, afirmação corroborada por Lopes e Furkotter (2009, p.4).

Enfatizamos a necessidade de se buscar um modelo de formação docente que comporte formas de apropriação crítica e contextualizada das TDIC (sic), de modo a possibilitar a exploração plena de seu potencial em ambientes de aprendizagem que permitam a alunos e professores redimensionarem os seus papéis (sic).

Nesta nova dimensão dos papeis a qual se referem os autores citados, a percepção das TDMIC como possibilidade de abertura de novos espaços educativos de construção do conhecimento é essencial e se apresentam como novas possibilidades no processo de ensino e aprendizagem.

Uma nova educação não se faz, sem um novo professor, elemento fundamental no processo de inovação pedagógica. Brilhantemente, Cysneiros (2006) complementa que o uso das tecnologias educacionais somente se aperfeiçoará se elas forem exploradas com ênfase no conteúdo e não na ferramenta.

As tecnologias móveis podem se tornar, enquanto recurso educacional, grandes aliadas no processamento das informações que se reflexem no aprendizado.

\footnotetext{
${ }^{1}$ Disponível em: http://www.capes.gov.br/educacao-basica/prodocencia. Acesso em: 12 ago. 2015
} 
Mas é importante ressaltar a necessidade de que os professores respondam ao desafio de modernização utilizando as TDMIC como aliadas em um processo de ensinoaprendizagem repleto de novas perspectivas e que exerçam seu papel docente de forma a estimular os alunos a repensarem suas ações, modificando a realidade onde estão inseridos e construindo uma nova história.

Quando olhamos a história do uso do computador na escola brasileira, constatamos que muito da dificuldade inicial de sua adoção pelos professores estava no fato de que eles não dispunham dessa tecnologia em suas casas, o que lhe dificultava o desenvolvimento de uma intimidade para lidar com ela. Com certeza a intimidade com o computador contribui para a confiança necessária para a sua adoção enquanto um recurso na escola. Com o tempo o computador, que antes estava apenas na escola, chegou às casas de praticamente todos os professores e ainda às dos alunos.

Quando olhamos os dispositivos móveis, vemos uma "migração" diferente. Antes de estar nas escolas, o telefone celular e os tablets chegam às casas, de professores e estudantes. Ali está a chance de os professores criarem uma intimidade com tais dispositivos, fazendo com que deixem de ser máquinas intimidadoras, como durante algum tempo foi o computador, visto, então, por muitos como uma "caixa preta".

Quando hoje consideramos a possibilidade de trazermos os dispositivos móveis para uso da escola, na perspectiva da aprendizagem, devemos considerar como vantagens o fato de que os usuários de alguma forma já dominam essas tecnologias e que eles mesmos se encarregam da posse e do seu funcionamento, incluindo sua manutenção. A escola fica dispensada de fornecer equipamentos aos professores e estudantes. Eventualmente precisará fornecer apenas o acesso wi-fi à internet para aqueles que não contam com conexão $3 \mathrm{G}$ ou $4 \mathrm{G}$ em seus dispositivos.

Por outro lado, a utilização de mídias sociais começa a acontecer na escola, de forma discreta, ainda não perfeitamente articulada à aprendizagem, essencialmente como espaço de comunicação de indivíduos em suas redes.

Dispositivos móveis e mídias sociais devem vir a ser usadas na escola? A resposta para essa questão ainda não está formulada.

Mas o que pensam os futuros professores, em sua maior parte jovens alunos das licenciaturas sobre isso? São eles usuários de dispositivos móveis? Utilizam as mídias sociais na construção de suas redes sociais virtuais? Vislumbram sua utilização na escola? As respostas para algumas dessas questões foram buscadas no presente estudo.

\section{Métodos e técnicas}

Para encontrarmos respostas para as nossas indagações, optamos por uma investigação do tipo survey. Um questionário on-line foi respondido por 59 (cinquenta e nove) estudantes, a maioria $(83,1 \%)$ do sexo feminino, de cinco licenciaturas de uma instituição de ensino superior localizada em Minas Gerais. Os resultados foram analisados com o concurso um pacote estatístico.

\section{Resultados}




\section{CBIE-LACLO 2015}

Anais dos Workshops do IV Congresso Brasileiro de Informática na Educação (CBIE 2015)

Apenas $22,8 \%$ dos estudantes dispõem de um tablet para uso pessoal, a maior parte deles com acesso wireless. Por outro lado, quase todos possuem telefones celulares, dos quais quase $85 \%$ são smartphones, com acesso $3 \mathrm{G} / 4 \mathrm{G}$ à internet.

Todos os estudantes informaram que acessam a internet, ao menos de forma ocasional, utilizando tecnologias móveis. A maior parte deles o faz quase que diariamente (Gráfico 1) e quase todos (98\%) utilizam mídias sociais, como Facebook, Twitter e WhatsApp.

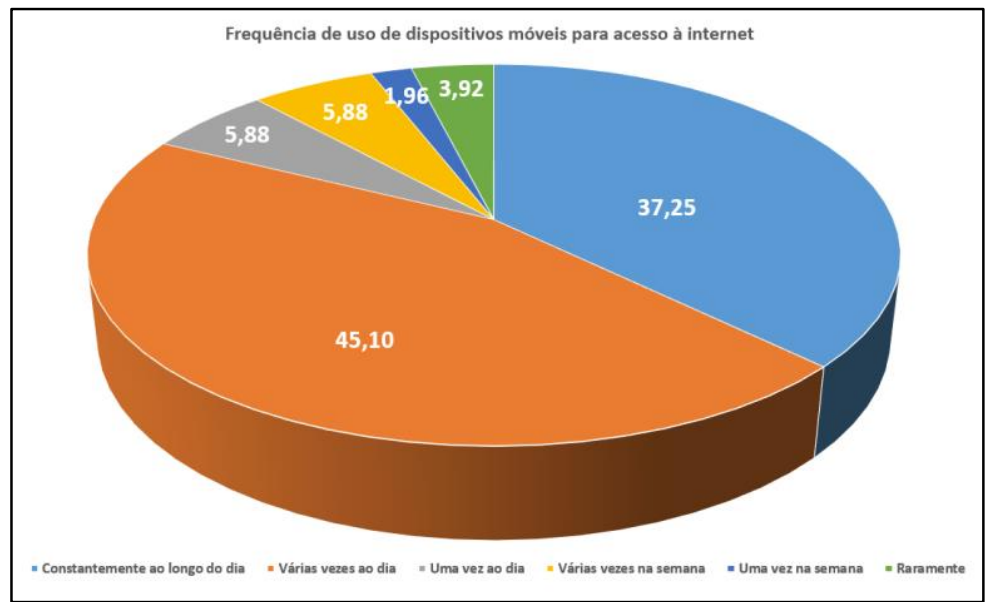

Gráfico 1 - Frequência de uso de dispositivos móveis para acesso à internet

Apenas um entrevistado informou não utilizar celular para enviar ou receber mensagens de textos. A quantidade média de mensagens de texto (SMS) que os estudantes enviar ou recebem diariamente é expressiva, ainda que bem distribuída nas diferentes faixas de quantitativos utilizadas no survey (Gráficos 2 e 3), ficando, contudo, bastante evidente que eles mais recebem do que enviam mensagens de textos.

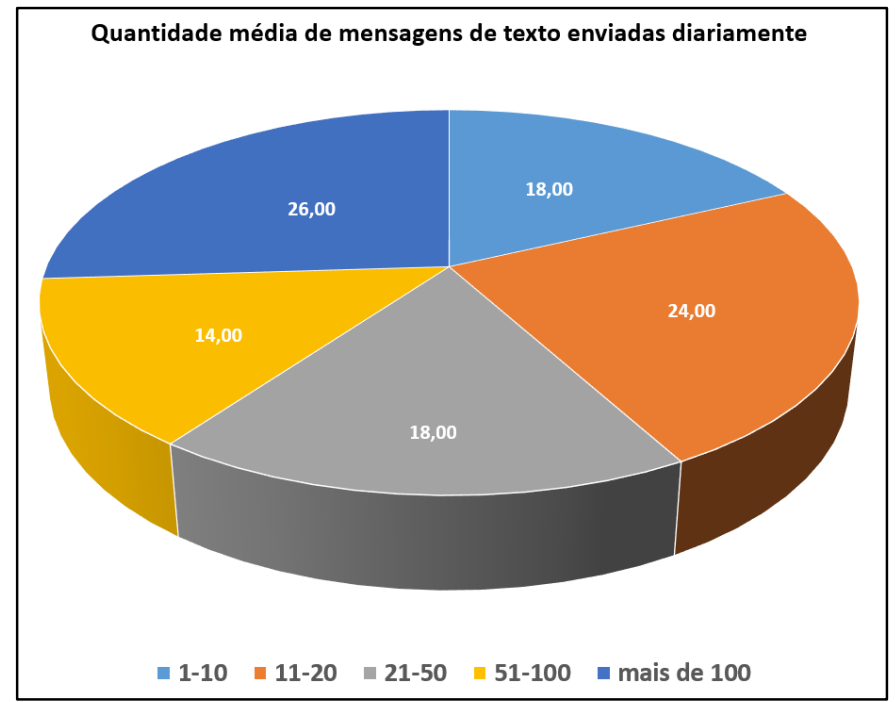

Gráfico 2 - Quantidade média de mensagens de texto enviadas diariamente 


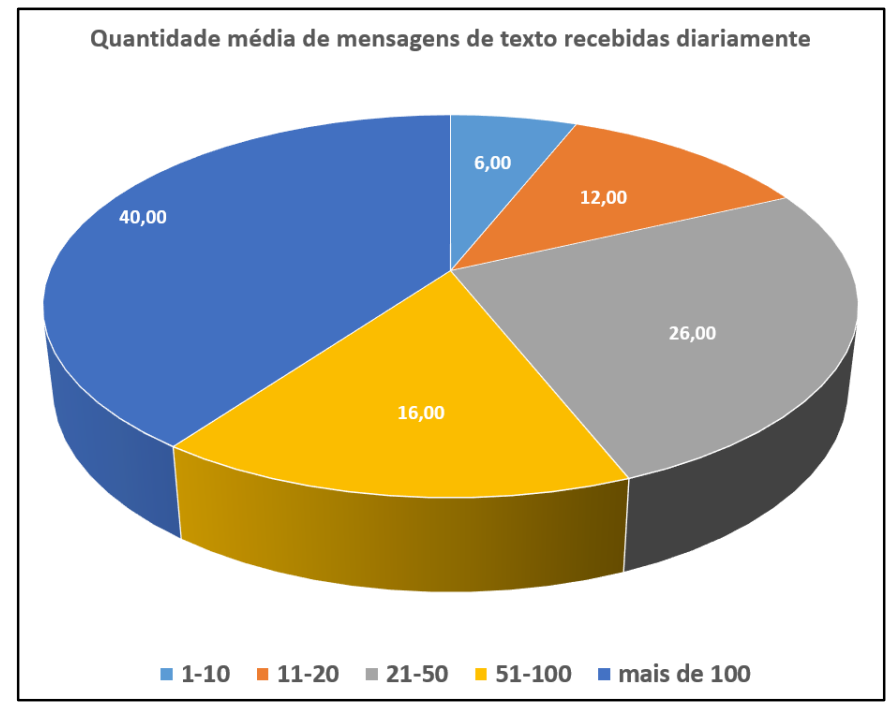

\section{Gráfico 3 - Quantidade média de mensagens de texto recebidas diariamente}

O app WhatsApp e o Facebook, possivelmente as principais "coqueluches" do momento, são as mídias sociais mais utilizadas pelos estudantes entrevistados, respectivamente por $98 \%$ e $96 \%$ deles. O Twitter tem baixa utilização (32\%) entre eles e o Instagram estaria em uma posição intermediária, com $58 \%$ de usuários entre os entrevistados.

Dos licenciandos que responderam a questão, 77,2\% afirmaram que têm certeza de que o uso de mídias sociais será útil na escola, apenas $1,8 \%$ não reconhecem esse valor.

Quando indagados se gostariam que seus professores utilizassem mídias sociais para comunicarem-se com eles, 73,7 \% responderam que sim, com certeza; 3,5\% disseram que não. Foi interessante notar que, quando indagados se gostariam que os professores utilizassem mídias sociais voltadas para a aprendizagem, 64,9\% dos respondentes disseram que sim, com certeza. $O$ índice dos que não gostariam de ver essa possibilidade sobe para 5,3\%.

\section{Conclusões}

O survey evidenciou que os estudantes são usuários de tecnologia móveis, prevalecendo, como seria normal esperar, o smartphone para a comunicação. Com as potencialidades que esse tipo de dispositivo oferece e considerado o fato de que seu preço declinou bastante, é natural que os usuários prefiram esse tipo de dispositivo.

Ademais, os estudantes são usuários de mídias sociais, pelo menos daqueles que, assim podemos dizer, estão na moda. Essa intimidade abre possibilidades para que seus professores utilizem esses recursos como forma de comunicação, principalmente, mas ainda como um recurso para a aprendizagem.

O uso dos dispositivos móveis e das mídias sociais para a comunicação entre os agentes dos processos de ensino e aprendizagem certamente estará mais facilitado, já que 
ele é o predominante nas vidas pessoais. Os indicadores inclusive do uso de SMS apontam nessa direção.

Já o uso com finalidade educacional, visando a aprendizagem com o concurso da tecnologia móvel, em uma cultura digital, exigirá preparo dos professores e ainda cria mais expectativas junto aos estudantes. Embora exista uma aceitação da possibilidade dessa utilização, haja vista que uma parte significativa dos estudantes informou que gostaria que seus professores fizessem esse tipo de uso, ela poderá aumentar, na medida em que as mídias sejam introduzidas curricularmente e os estudantes comecem a identificar a utilidade. Isso poderá significar inclusive o uso dos dispositivos móveis, especialmente os smartphones, na própria sala de aula. Assim, aquele aparelho que hoje é motivo de repulsa por boa parte dos professores, pela perturbação que traria ao ambiente de aprendizagem, poderá passar a ser tecnologia presente em cada sala de aula, na mão de cada estudante, no uso 1:1, um recurso para a sua aprendizagem e não para a dispersão, provocada não pela presença da tecnologia, mas pela aula que não traz significado para eles $^{2}$.

Os resultados de todo o survey revelaram aspectos bastante interessantes, provocando outras questões que certamente poderão desencadear novas investigações.

E, por certo, já que as tecnologias cambiam rapidamente, novas questões sobre o uso educacional das tecnologias móveis e informação e comunicação e de espaços da internet sempre serão provocadores de novas pesquisas.

\section{Referências}

ALVES, L. M, ROCHA, E. (2010) Publicidade online: o poder das mídias e redes sociais. Fragmentos de cultura. v. 20, n. 3.

AKERMAN, M., PESSONI, A. (2014) O uso das mídias sociais para fins de ensino e aprendizagem: estado da arte das pesquisas do tipo survey. ECCOM, v. 5, n. 10.

APPLE, M. W. (1982) Ideologia e currículo. São Paulo: Brasiliense, 246p.

BARCELLOS, G. T. (2012) Redes sociais e formação de professores. Perspectiva online. v. 5 , n.2.

BELL, D. (1977) O advento da sociedade pós-industrial: uma tentativa de previsão social. São Paulo: Cultrix, 540p.

BRASIL. Parecer CNE/CES n. 1301 de 06 de novembro de 2001. Regulamenta das Diretrizes Curriculares Nacional para os cursos de Licenciatura em Ciências Biológicas. Diário Oficial da União, Brasília, 07 dez. 2001. Disponível em <http://portal.mec.gov.br/cne/arquivos/pdf/CES1301.pdf>. Acesso em: 12 ago. 2015

BRASIL. Parecer CNE/CES n. 01 de 15 de maio de 2006. Regulamenta das Diretrizes Curriculares Nacional para os cursos de Licenciatura em Pedagogia. Diário

\footnotetext{
${ }^{2} \mathrm{O}$ deputado federal Alceu Moreira (PMDB/RS) submeteu à Câmara Federal um projeto de lei que proíbe o uso de dispositivos móveis, como celulares e tablets, nas salas de aula da Educação Básica e da Educação Superior de todo o país, exceto quando "inseridos no desenvolvimento de atividades didático pedagógicas $e$ devidamente autorizados pelos docentes ou corpo gestor". O projeto stá disponível em http://www.camara.gov.br/proposicoesWeb/prop_mostrarintegra?codteor=1296954\&filename $=P L+104 / 2$ 015 .
} 
CBIE-LACLO 2015

Anais dos Workshops do IV Congresso Brasileiro de Informática na Educação (CBIE 2015)

Oficial da União, Brasília, 16 mai. 2006. Disponível em

<http://portal.mec.gov.br/cne/arquivos/pdf/rcp01_06.pdf>. Acesso em: 12 ago. 2015

BROUGÈRE, G., ULMANN, A. (2012) (Org.). Aprender pela vida cotidiana. Campinas, SP: Autores Associados. (Coleção formação de professores).

CASTELlS, M. (1999) A sociedade em rede. São Paulo: Paz e Terra. 698 p. (A era da informação. Economia, sociedade e cultura; 1) ISBN 9788577530366

CIRIBELI, J. P., PAIVA, V. H.P (2011) Redes e mídias sociais na internet: realidades e perspectivas de um mundo conectado. Mediação. v. 13, n. 12.

CLIFFORD, M. Bring Your Own Device (BYOD): 10 Reasons Why It's a Good Idea. Disponível em

<https://plus.google.com/u/0/101796324413630088793\#ixzz3iiioDedyhttp://www.teach thought.com>. Acesso em: 12 agosto de 2015.

CYSNEIROS, P. G. Gestão de Tecnologias da Informação e comunicação na escola. Recife, 2006. Disponível em:

<www.moodle.ufba.br/mod/resource/view.php?id=1370>. Acesso em: 12 agosto de 2015 .

FERRETE, A. A.S. S., \& FERRETE, R. B. Tecnologias Móveis no ambiente escolar: desafios e reflexões. In: $3^{\circ}$ Congresso Brasileiro de Informática em Educação (CIBIE ) Workshops (WCIBIE ). 2014, Dourado/MS. Anais Eletrônicos...Dourado. Disponível em <http://www.br-ie.org/pub/index.php/wcbie/index>. Acesso em 13 Ago. 2015

GSMA. Economía Móvil: América Latina. 2014t. London, 2011. Disponível em <http://latam.gsmamobileeconomy.com/>. Acesso em: 02 Jun. 2015

FÜRKOTTER, M., LOPES, R. P. Tecnologias digitais de informação e comunicação (TDIC) no Currículo formal dos cursos de formação de professores das Universidades públicas paulistas. 2009. Disponível em <http://www.anped.org.br/reunioes/32ra/arquivos/posteres/GT12-5484--Int.pdf>. Acesso em: 12 agosto 2015

MACHADO, J. R., TIJIBOY, A. V. (2005) Redes sociais virtuais: um espaço para efetivação da aprendizagem cooperativas. Novas tecnologias na Educação. v. 3, n. 1.

MARINHO, S. P. P. et al. (2014). APP currículo, escola e mobilidade. In: XXV Simpósio Brasileiro de Informática na Educação, 2014b, Dourados-MS, Anais... Workshops Congresso Brasileiro de Informática na Educação. Disponível em <http://www.br-ie.org/pub/index.php/wcbie/article/view/3234>. Acesso em 29 jan. 20014.

SERPA, C. A. (1999) Educação no Brasil está no caminho certo. Folha Dirigida, 15 out. Suplemento Especial Dia do Professor, p.27.

UNESCO. Diretrizes de políticas para a aprendizagem móvel. 2013. Disponível em <http://unesdoc.unesco.org/images/0022/002277/227770por.pdf〉. Acesso em: 11 fev. 2015.

O grupo de pesquisas "Tecnologias digitais em Educação", da PUC Minas, constante no Diretório do CNPq, conta com apoio do CNPq e da FAPEMIG. 